\title{
Model Gaya Hidup Konsumen Dalam Memilih Produk Makanan Dalam Negeri
}

\author{
Reny Andriyanty*, Haswan Yunaz \\ Institut Bisnis dan Informatika Kosgoro 1957 \\ Jl. M.Kahfi II No.33 Jagakarsa, Jakarta Selatan Indonesia 12620 \\ *Email : r.andriyanty@gmail.com
}

\begin{tabular}{|c|c|}
\hline Artikel Info & ABSTRAK \\
\hline $\begin{array}{c}\text { Dikirim: } \\
\text { 27 Januari } 2020 \\
\text { Revisi: } \\
28 \text { Maret } 2020 \\
\text { Diterima: } \\
20 \text { April } 2020\end{array}$ & $\begin{array}{l}\text { Penelitian ini bertujuan untuk mendapatkan informasi mengenai hubungan antara gaya hidup generasi } \\
\text { muda terkait konsumsi makanan dan minuman produk dalam negeri khususnya warteg. Penelitian ini } \\
\text { menggunakan metode deskriptif dengan sampel berjumlah } 100 \text { orang. Data dianalisis secara tabulasi } \\
\text { kemudian akan dilakukan analisis mutlivarians melalui pemodelan persamaan struktural. Model yang } \\
\text { dikembangkan } 70,7 \text { persen terwakili oleh variabel eksogen. Motif konsumsi berupa motif ekonomi dan } \\
\text { sosial yang berkembang di generasi, pengalaman yang menyenangkan atas konsumsi produk makanan } \\
\text { dalam negeri yang dirasakan generasi muda, persepsi konsumen mengenai nilai cinta bangsa dan negara } \\
\text { yang berbentuk tindakan konsumsi produk dalam negeri dan sikap konsumen yang menghargai produk } \\
\text { dalam negeri berpengaruh terhadap pengembangan gaya hidup cinta produk dalam negeri. }\end{array}$ \\
\hline
\end{tabular}

Kata Kunci: Generasi Muda, Produk Dalam Negeri, Gaya Hidup.

\section{Consumer Lifestyle Models in Choosing Domestic Food Products}

\begin{abstract}
The research objection are to obtain information about the relationship between the young generation lifestyle that related to the domestic food and beverage products consumption (case of warteg). The research methods was descriptive method with 100 samples. The data analyzed by mutlivariance analysis with structural equation modeling. The developed research model 70.7 percent is represented by exogenous variables. Consumption motives in the form of economic and social motives that developed in the young generation, the pleasant experiences of domestic food products consumption, the consumers' perceptions about ethnocentrism and consumer attitudes that appreciate the domestic product are influencing factors for "love domestic product " lifestyle among the young generation.
\end{abstract}

Keywords: Young Generation, Domestic product, Lifestyle

Cara Sitasi :

Andriyanty, R., \& Yunaz, H. (2020). Model Gaya Hidup Konsumen Dalam Memilih Produk Makanan Dalam Negeri. Jurnal Ilmiah Manajemen dan Bisnis, 21(1), 82-95. https://doi.org/10.30596/jimb.v21i1.4024. 


\section{PENDAHULUAN}

Penyedia produk makanan di DKI Jakarta masih didominasi oleh pemilik warga negara Indonesia. Berdasarkan data persentase banyaknya usaha penyediaan makanan dan minuman berdasarkan kepemilikan modal menurut provinsi di pulau Jawa tahun 2017, DKI Jakarta memiliki kepemilikan warga negara asing tertinggi dibandingkan provinsi lainnya. Hal ini dapat dilihat pada grafik berikut ini :

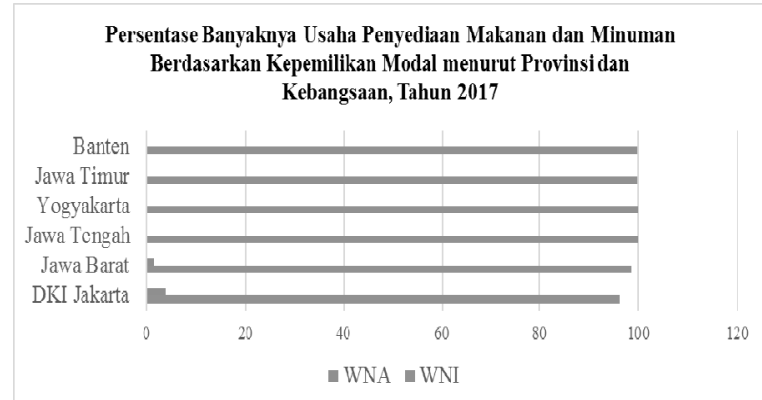

Gambar 1. Persentase banyaknya usaha penyediaan makanan dan minuman berdasarkan kepemilikan modal menurut provinsi di pulau Jawa tahun 2017. (Sumber: BPS, 2019).

Gambar 1, apabila dibandingkan dengan pendapatan yang diterima usaha makanan\& minuman di DKI Jakarta berdasarkan asal konsumen, pendapatan tertinggi diperoleh dari konsumen lokal dengan nilai mencapai 16 miliar. Hal tersebut dapat dilihat pada gambar berikut :

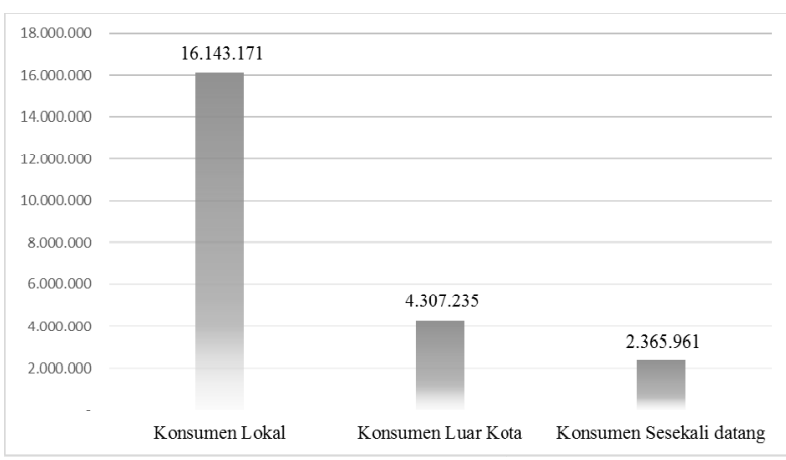

Gambar 2. Jumlah pendapatan usaha makanan\& minuman di DKI Jakarta berdasarkan asal konsumen (dalam juta rupiah) (Sumber: BPS, 2019).
Konsumen lokal menyumbang pendapatan terbesar bagi bisnis makanan dan minuman di DKI Jakarta. Dan dibandingkan dengan persentase penduduk berdasarkan kelompok umur di DKI Jakarta pada tahun 2019, Kelompok umur 20 sampai 34 tahun merupakan kelompok umur dengan persentase kedua terbesar setelah kelompok umur diatas 35 tahun. Nilai ini memberi harapan dalam konsumsi produk makanan dan minuman dalam negeri pada generasi muda di DKI Jakarta. Secara lebih jelasnya, hal tersebut dapat dilihat pada gambar berikut:

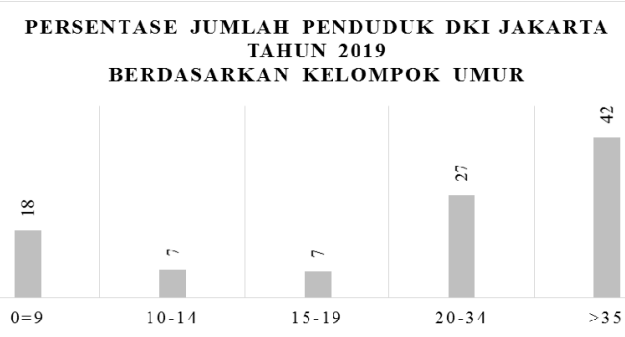

Gambar 3. Jumlah persentase penduduk DKI Jakarta berdasarkan kelompok umur ( Sumber: Data BPS DKI Jakarta 2019 (diolah).

Saat ini generasi muda cenderung memiliki gaya hidup hedonis. Gaya hidup yang berfokus pada pengejaran kesenangan pribadi, personal dan cenderung mengkonsumsi produk bukan kebutuhan (Ramadhan and Simanjuntak, 2018; Eren, Eroğlu and Hacioglu, 2012; Hamzah et al., 2014; Asayesh and Hamid, 2011). Penelitian Andriyanty dan Wahab (2019) menyebutkan bahwa 80,28 persen generasi $\mathrm{Z}$ ternyata lebih menyukai produk dalam negeri dibandingkan produk luar (Andriyanty and Wahab, 2019). Namun hasil studi Özdemir et al menyebutkan bahwa hedonisme mempengaruhi tingkat konsumsi generasi muda atas makanan dan minuman (Özdemir and Kongresi, 2019). Bagaimana dengan gaya hidup generasi muda Indonesia? Apakah mereka cenderung hedonis? Apakah generasi muda Indonesia memiliki gaya hidup yang 
cenderung untuk mengkonsumsi produk makanan dan minuman dalam negeri dibandingkan produk luar negeri? Berdasarkan data diatas, maka perlu dianalisis mengenai peran gaya hidup generasi muda terkait pola konsumsi makanan dan minuman produk dalam negeri.

Generasi muda dengan tendensi individualis dan memiliki gaya hidup hedonis (Asayesh and Hamid, 2011; Eren, Eroğlu and Hacioglu, 2012; Dascălu, 2014; Hamzah et al., 2014; Masood, Musarrat and Mazahir, 2017; Ramadhan and Simanjuntak, 2018; Özdemir and Kongresi, 2019). Penelitian Özdemir et al menunjukkan bahwa hedonisme berpengaruh terhadap konsumsi makanan jalanan. Salah satu kategori makanan jalanan di Indonesia adalah Warteg. Warung tegal adalah tipologi warung skala menengah kebawah dengan menu nasi dan lauk pauk yang didirikan oleh orang dari daerah Tegal. Bisnis warteg cenderung dikategorikan pada rumah makan cepat saji dengan aneka lauk dan sayur mayur yang bisa dipilih dan diambil sendiri oleh konsumen dan lebih berbudaya Indonesia (Andayani, 2015). Namun generasi muda memiliki persepsi warung tegal yang tidak keren (Ramdhon, 2018) dan murahan cenderung membuat keengganan generasi muda untuk mengkonsumsinya. Hal ini memerlukan analisis secara mendalam apakah gaya hidup generasi muda mempengaruhi generasi muda dalam mengkonsumsi produk makanan dan minuman dalam negeri dalam hal ini adalah konsumsi warteg. Penelitian ini bertujuan untuk mendapatkan informasi mengenai hubungan antara gaya hidup generasi muda terkait konsumsi makanan dan minuman produk dalam negeri khususnya warteg.

\section{METODE}

Penelitian ini menggunakan metode deskriptif. Unit penelitian adalah konsumen warteg yang tersebar di dua wilayah penelitian di Jakarta Selatan. Sampel penelitian akan ditentukan dengan metode non-probability sampling secara accidental sampling. Teknik pengambilan data adalah wawancara terstruktur dengan bantuan kuisioner. Kuisioner dibagikan kepada responden yang mengkonsumsi makanan dari warteg dan dicari yang termasuk dalam kategori generasi muda yang berusia 25 tahun kebawah dan dengan sampel berjumlah 100 orang. Penentuan repsonden akan dilakukan secara berkebetulan (accidental sampling). Sumber data adalah primer dan sekunder Data yang diperoleh akan dianalisis secara tabulasi kemudian akan dilakukan analisis mutlivarians melalui pemodelan persamaan struktural. Jenis data yang digunakan adalah data primer dan untuk mengukur tingkatan persepsi responden didesain dengan skala Linkert positif. Responden diminta untuk menilai persepsinya berdasarkan kuisioner penelitian. Nilai terendah diberi nilai 1 , dan tertinggi diberi nilai 5. Tingkat persetujuan dalam riset ini adalah pendapat responden dengan gradasi dan bobot nilai sesuai tabel berikut ini :

Tabel 1. Gradasi persepsi dan bobot nilai gaya hidup generasi muda.

\begin{tabular}{lc}
\hline \multicolumn{1}{c}{ Gradasi } & Bobot nilai \\
\hline persepsi & \\
\hline Sangat tinggi & 5 \\
Tinggi & 4 \\
Sedang & 3 \\
Rendah & 2 \\
Sangat rendah & 1 \\
\hline
\end{tabular}

Kerangka konseptual dalam penelitian ini dibentuk dari persepsi generasi muda atas gaya hidup mereka dan pilihan mereka terjadap produk makanan dalam negeri (dalam penelitian ini difokuskan pada makanan warteg). Secara teori istilah gaya hidup pertama kali masih diperdebatkan, namun sosiolog Max Weber (1864-1920) dan dan psikolog Alfred Adler (1870-1937) memperkenalkan istilah gaya hidup. Pemaknaan gaya hidup adalah persamaan status kehormatan yang lebih dimaknai pada kegiatan konsumsi dengan pola yang sama 
sehingga seorang individu dapat menunjukkan status sosialnya saat berada didalam kelompok sosialnya. Aspek penting dalam bidang ekonomi adalah pada pembuatan pilihan yang bijaksana diantara banyak pilihan gaya hidup (Tittenbrun, 2017). Gaya hidup mengacu pada bagaimana seorang individu hidup, menangani masalah dan hubungan interpersonalnya. Adler menyebutkan bahwa gaya hidup adalah sebuah pohon individual dimana ia dapat mengeksperisikan serta membentuk dirinya sendiri dalam lingkungannya dengan hubungan saling mempengaruhi (Boeree et al., 2006).

Belakangan konsep gaya hidup diterapkan oleh William Lazer dalam konsep pemasaran. Dan menurut Alfred Adler, setiap individu memiliki gaya hidupnya sendiri yang berbeda yang bisa lebih atau lebih kurang mirip dengan gaya hidup individu lain, tetapi tidak pernah persis sama. Gaya hidup berkembang melalui kekuatan kreatif gaya endogen individu selama tahun-tahun pertama masa kanak-kanak dan bukan karena faktor keturunan atau lingkungan. Selain menjadi akar individualitas, gaya hidup menciptakan kesatuan perilaku - dari 'pikiran, emosi dan tindakan, baik sadar maupun tidak sadar 'yang mencerminkan' arah yang dipilih oleh individu untuk usahanya. ' Dengan kata lain, itu adalah prinsip panduan yang membentuk semua pengalaman dan perintah semua bentuk ekspresi dalam mengejar tujuan keunggulan yang unik individu (Adler, 1956, hal.175 dalam Uth, Lahrmann and Pedersen, 1996). Viel menyatakan bahwa gaya hidup adalah pelibatan kegiatan: termasuk didalamnya pola konsumsi, kegiatan rekreasi dan praktik domestik yang mencakup gaya memasak / makan, praktik membesarkan anak, rumah gaya dekorasi/perabotan, dan kegiatan yang harus dilakukan dengan hubungan pribadi, kekerabatan dan pemeliharaan rumah. Gaya hidup kemudian, pada tahap ini, dapat diidentikasi secara penuh pada berbagai kegiatan sehari-hari, termasuk pola konsumsi, kegiatan rekreasi, praktik domestik dan aktivitas kerja berbayar. Dan dapat didefinisikan sebagai pola khas atau karakteristik perilaku pribadi dan sosial seorang individu atau kelompok (Veal, 1993). Berdasarkan teori perilaku, perilaku manusia dibimbing oleh tiga jenis pertimbangan: (a) keyakinan tentang kemungkinan konsekuensi dari perilaku dan evaluasi konsekuensi ini (keyakinan perilaku), (b) keyakinan tentang harapan orang lain dan motivasi untuk mematuhinya harapan (kepercayaan normatif) dan (c) keyakinan tentang faktor yang diharapkan untuk membantu atau menghambat kinerja perilaku dan pentingnya persepsi ini sebagau faktor kontrol atas keyakinan tersebut (Maio et al., 2007a).

Terdapat konsepsi menarik berdasarkan penelitian Moreno et $\underline{\text { al, }}$ yang menyatakan bahwa generasi muda terutamanya generasi milineal adalah celah pasar yang potensial. Generasi ini memilih produk berdasarkan kemauan dan identitas individu mereka sendiri, memiliki kemampuan menciptakan trend, dapat mempengaruhi konsumsi rekanrekannya (Moreno et al., 2017). Berdasarkan hal tersebut, gaya hidup generasi muda memiliki kecenderungan untuk mengikuti ide-ide kreatif dalam dirinya, konsep diri, pengejaran kebahagian pribadai namun berpotensi untuk saling mempengaruhi lingkungannya.(Jasimah bt. Wan Mohamed Radz, Murad and Osman, 2005; Sharif et al., 2013; Budac and Baltador, 2014; Ahmed et al., 2018; Ting et al., 2018). Sebagian besar generasi muda saat ini mencoba hidup di dunia yang lebih kompleks dan tampaknya menjadi masalah perilaku bagi generasi diatasnya (Ting et al., 2018). Generasi muda bertendesi memilih makanan diluar rumah dan menjadi pengalaman baru, menggemari makanan dan minuman ringan yang diiringi dengan aktivitas kerja otak alih-alih kegiatan fisik (Syahrul et al., 2016; Ahmed et al., 2018). Kondisi tersebut memerlukan modifikasi perilaku (Joshi, 2012). Pengambilan keputusan generasi muda 
terutamanya generasi milineal terkait pembelian produk lebih cepat daripada pada generasi sebelumnya, akibat akses ke informasi yang dapat diperoleh dengan cara elektronik untuk melakukan pembelian dan berkonsultasi dengan pendapat mereka yang sudah melakukan. Generasi milineal juga menganggap pandangan orang lain di situs web dapat menjadi referensi mereka untuk membeli (Moreno et al., 2017). Kondisi tersebut, membuat generasi muda memiliki karakteristik yang berbeda dalam konsumsi atas produksi makanan dan minuman. Penelitian Ramadania et al di Kalimantan Barat kepada 446 responden berusia antara 31 sampai 40 tahun menunjukkan bahwa sikap cinta produk dalam negeri yang dimiliki konsumen memiliki efek negatif yang kuat pada sikap terhadap produk asing. Semakin tinggi kecintaan pelanggan terhadap produk dalam negeri, semakin tinggi pula penolakan terhadap produk asing. Studi ini juga menunjukkan efek positif dari kurangnya ketersediaan produk dalam negeri, sehingga mengalihkan kebutuhannya pada produk asing ditahap evaluasi konsumen terhadap produk asing (Ramadania, Gunawan and Rustam, 2015). Hasil ini kontradiktif dengan penelitian Karoui et at yang menyatakan bahwa konsumen di negara berkembang secara umum memiliki tingkat kecintaan terhadap produk dalam negeri yang rendah (Karoui and Khemakhem, 2019). Kondisi ini yang memerlukan analisis mendalam mengenai konsumsi produk makanan dan minuman dalam negeri pada generasi muda Indonesia terkait gaya hidup yang yang sangat terpapar perilaku hedonis. Gaya hidup dapat diartikan secara plularistik. Dalam konsep sosiologi, gaya hidup dapat dinyatakan ekspresi dari individu manusia. Gaya hidup adalah manifestasi dari subkultur, keluarga, kelas sosial, teman (status kelompok, jenis kelamin, generasi dan berbagai pengaruh lainnya. Sehingga dapat dikatakan bahwa gaya hidup secara visual akan membedakan satu subkultur dari yang lain atau dari budaya dalam arti yang lebih luas. Begitu juga dengan gaya hidup secara visual mengekspresikan hubungan seseorang di dalam grupnya (Jensen, 2007).

Gaya hidup tidak hanya dipengaruhi oleh minat, tuntutan, kemampuan dan kemungkinan individu, tetapi merupakan fenomena rumit dengan kelas sosial, strata sosial, jenis barang konsumsi (bahan atau budaya), pendapatan, struktur sosial, nilai sosial, model referensi, termasuk didalamnya kondisi ekonomi suatu bangsa. Meskipun setiap individu mampu membuat pilihan pribadi atas dasar kehendak dan permintaannya sendiri, ia akan tetap mempertimbangkan pendapatannya, fasilitas keuangan, daya beli, harga barang, selera dan kemauan serta nilai-nilai yang dia yakini dan andalkan, pilihan pribadi yang juga dipengaruhi oleh faktor sosial, variabel demografis (usia, jenis kelamin, tempat lahir, jenis pekerjaan, dan lainnya (Rizi and Sabeghi, 2015). Gaya hidup menangkap aspek yang relevan dari konsumen, seperti kepribadian, petunjuk, motif, minat, sikap, kepercayaan dan nilai-nilai. Ketika studi menjadi berorientasi pada produk tertentu, konsumen harus merespons pernyataan yang terkait pada produk, merek, layanan, situasi, dan banyak faktor lainnya (Sathish and Rajamohan, 2012). Konsep analisis gaya hidup dalam pemasaran konevensional cenderung mensegmentasikan pasar menggunakan variabel dari ilmu sosial terutama ilmu psikologi sosial yang dikombinasikan dengan faktor demografis seperti usia, ras, jenis kelamin. Hal itu didasari oleh premis bahwa orang yang serupa dalam hal-hal seperti sikap, pendapat, motivasi, orientasi, akses ke sumber daya, nilai-nilai, dan minat memiliki kecenderungan terhadap pilihan konsumsinya (Ahuvia, Carroll and Yang, 2016). Persamaan path analysis terdiri atas outer dan inner model, dengan persamaan matematika untuk inner model adalah : 


\section{Jurnal Ilmiah Manajemen dan Bisnis}

$\eta=\tau_{1} \xi_{1}+\tau_{2} \xi_{2}+\tau_{3} \xi_{3}+\tau_{4} \xi_{4}+\tau_{4} \xi_{4}+t_{1}$ Dimana $\eta=$ gaya hidup generasi muda mengkonsumsi produk makanan dan minuman dalam negeri; $\tau_{1}=$ koefisien sikap; $\xi_{1}=$ Faktor sikap; $\tau_{2}=$ koefisien pengalaman; $\xi_{2}=$ faktor pengalaman; $\tau_{3}=$ koefisien pribadi; $\xi_{3}=$ faktor pribadi; $\tau_{4}=$ koefisien motif; $\xi_{14}=$ faktor motif; $\tau_{5}=$ koefisien persepsi; $\xi_{5}=$ faktor persepsi; $t_{1}=$ nilai kesalahan dari variabel laten eksogen. Outer model dibentuk dengan persamaan matematika sebagai berikut :

1. Variabel laten eksogen

$$
\begin{aligned}
& \mathrm{x}_{1}=\text { sistem nilai }=\lambda_{\mathrm{x} 1} \xi_{1}+\delta_{1} \\
& \mathrm{x}_{2}=\text { konsistensi sikap }=\lambda_{\mathrm{x} 2} \xi_{2}+\delta_{2} \\
& \mathrm{x}_{3}=\text { standar pribadi }=\lambda_{\mathrm{x} 3} \xi_{3}+\delta_{3} \\
& \mathrm{x}_{4}=\text { pengalaman diri sendiri }=\lambda_{\mathrm{x} 4} \xi_{4}+ \\
& \delta_{4} \\
& \mathrm{x}_{5}=\text { pengalaman keluarga }=\lambda_{\mathrm{x} 5} \xi_{5}+\delta_{5} \\
& \mathrm{x}_{6}=\text { pengalaman orang lain }=\lambda_{\mathrm{x} 6} \xi_{6}+\delta_{6} \\
& \mathrm{x}_{7}=\text { tingkat pemahaman "aku cinta } \\
& \text { produk DN" }=\lambda_{\mathrm{x} 7} \xi_{7}+\delta_{7} \\
& \mathrm{x}_{8}=\text { pengaruh sosial }=\lambda_{\mathrm{x} 8} \xi_{8}+\delta_{8} \\
& \mathrm{x}_{9}=\text { Emosi }=\lambda_{\mathrm{x} 9} \xi_{9}+\delta_{9} \\
& \mathrm{x}_{10}=\text { Motif Ekonomi }=\lambda_{\mathrm{x} 1} \xi_{10}+\delta_{10} \\
& \mathrm{x}_{11}=\text { Motif Sosial }=\lambda_{\mathrm{x} 11} \xi_{11}+\delta_{11}
\end{aligned}
$$

$\mathrm{x}_{12}=$ Karakteristik Budaya $=\lambda_{\mathrm{x} 12} \xi_{12}+$

$\delta_{12}$

$\mathrm{x}_{13}=$ Karakteristik keluarga $=\lambda_{\mathrm{x} 13} \xi_{13}+$ $\delta_{13}$

2. Variabel laten endogen

$$
\begin{aligned}
& \mathrm{y}_{1}=\text { pribadi }=\lambda \mathrm{y}_{1} \eta_{1}+\varepsilon_{1} \\
& \mathrm{y}_{2}=\text { Pengalaman }=\lambda \mathrm{y}_{2} \eta_{2}+\varepsilon_{2} \\
& \mathrm{y}_{3}=\text { Kelas Referensi }=\lambda \mathrm{y}_{3} \eta_{3}+\varepsilon_{3} \\
& \mathrm{y}_{4}=\text { Keluarga }=\lambda \mathrm{y}_{4} \eta_{4}+\varepsilon_{4} \\
& \mathrm{y}_{5}=\text { Budaya }=\lambda \mathrm{y}_{5} \eta_{5}+\varepsilon_{5}
\end{aligned}
$$

\begin{tabular}{|c|c|c|c|c|c|}
\hline & $\mathrm{N}$ & Minimum & Maximum & Mean & Std. Deviation \\
\hline Tk.Pendapatan & 74 & Rp600.000 & Rp8.000.000 & Rp2.625.676 & Rp1.659.762 \\
\hline Usia & 100 & 17,00 & 23,00 & 21,5600 & 3,66617 \\
\hline Sistem Nilai & 100 & 1,00 & 5,00 & 3,6000 & ,82878 \\
\hline Konsistensi Sikap & 100 & 2,00 & 5,00 & 3,6600 & ,83145 \\
\hline Standar pribadi & 100 & 1,00 & 5,00 & 3,1400 & ,98494 \\
\hline Pengalaman Orang lain & 100 & 1,00 & 5,00 & 3,6300 & ,88369 \\
\hline Pengalaman Pribadi & 100 & 2,00 & 5,00 & 3,7300 & ,87450 \\
\hline Pengalaman Keluarga & 100 & 2,00 & 5,00 & 3,7300 & ,81470 \\
\hline Tingkat Pengetahuan & 100 & 1,00 & 5,00 & 3,8000 & ,81650 \\
\hline Pengaruh Sosial & 100 & 2,00 & 5,00 & 3,9400 & ,81427 \\
\hline Emosi & 100 & 1,00 & 5,00 & 3,2400 & ,99615 \\
\hline Motif Ekonomi & 100 & 1,00 & 5,00 & 3,3300 & ,86521 \\
\hline Motif Sosial & 100 & 1,00 & 33,00 & 4,1400 & 3,06172 \\
\hline Karakteristik budaya & 100 & 2,00 & 5,00 & 3,5900 & ,69769 \\
\hline Karakteristik Keluarga & 99 & 3,00 & 5,00 & 3,9394 & ,80582 \\
\hline Gaya Hidup & 100 & 2,00 & 5,00 & 4,1300 & 84871 \\
\hline Kelas Referensi & 100 & 2,00 & 5,00 & 4,1100 & ,75069 \\
\hline Keluarga & 100 & 2,00 & 5,00 & 3,6600 & ,85540 \\
\hline Pengalaman & 100 & 1,00 & 5,00 & 4,0400 & ,81551 \\
\hline Pribadi & 100 & 1,00 & 5,00 & 3,8100 & ,82505 \\
\hline Valid N (listwise) & 73 & & & & \\
\hline
\end{tabular}

Seluruh data ditabulasi dengan aplikasi sofware Excel dan dianalisis dengan aplikasi software SmartPLS 3.

\section{HASIL}

Responden penelitian adalah pembeli makanan produk dalam negeri yang mengkonsumsi makanan dari warteg. Secara statistik, demograsi responden adalah berumur antara 17 sampai 23 tahun dengan rata-rata usia adalah 21 tahun. Tingkat pendapatan berada diantara Rp.600.000 sampai Rp.8.000.000 per bulan. Rata-rata pendapatan responden adalah Rp.2.625.676. Data terinci dapat dilihat pada tabel berikut :

Tabel 2. Statistik Deskriptif Data Responden Penelitian. 
Berdasarkan Tabel 2, maka responden cenderung pada kelompok masyarakat ekonomi menengah dan bawah. Hal tersebut sejalan dengan penelitian Novianti et al yang menyebutkan bahwa seiring waktu warteg mampu menyangga masyarakat miskin di perkotaan dalam penyediaan pangan lokal yang murah termasuk didalamnya peran bisnis warteg yang dapat menampung banyak tenaga kerja (Novianti et al., 2018). Penelitian ini mengembangkan model antar variabel gaya hidup generasi muda dalam mengkonsumsi produk makanan dalam negeri. Variabel gaya hidup merupakan kombinasi antar faktor sikap hidup, pengalaman generasi muda terkait produk makanan warteg, gaya kepribadian generasi muda, motif mereka dalam berbelanja serta persepsi generasi muda atas produk warteg, baik atau buruk. Variabel manifest untuk gaya hidup adalah pola kepribadian generasi muda terhadap produk dalam negeri, pengalaman mereka terhadap produk dalam negeri, kelas referensi yang dimiliki oleh generasi muda, peranan keluarga terkait gaya hidup cinta produk dalam negeri serta peranan budaya.
Variabel manifest untuk sikap, diproksi dengan sistem nilai yang dianut generasi muda terkait produk dalam negeri, konsistensi sikap mereka terhadap produk dalam negeri dan standar hidup generasi muda itu sendiri. Variabel manifest pengalaman adalah pengalaman pribadi mereka, pengalaman keluarga dan pengalaman orang lain terhadap produk dalam negeri yang mempengaruhi gaya hidup generasi muda saat ini. Variabel manifest untuk kepribadian adalah tingkat pengetahuan tentang pentingnya produk dalam negeri, pengaruh sosial dan emosi terkait konsumsi produk dalam negeri. Motif didekati dengan variabel manifest motif ekonomi dan motif sosial. Variabel manifest persepsi generasi muda yang diduga mempengaruhi gaya hidup adalah karakteristik budaya bangsa Indonesia dan karakteristik keluarga.

Berdasarkan uji validitas dan realibilitas dengan menggunakan nilai factor loading tehadap data penelitian menunjukan bahwa variabel manifest dari variabel laten adalah valid (seluruh nilai $\geq 0,50$ ). Data rinci dapat dilihat pada gambar berikut ini :

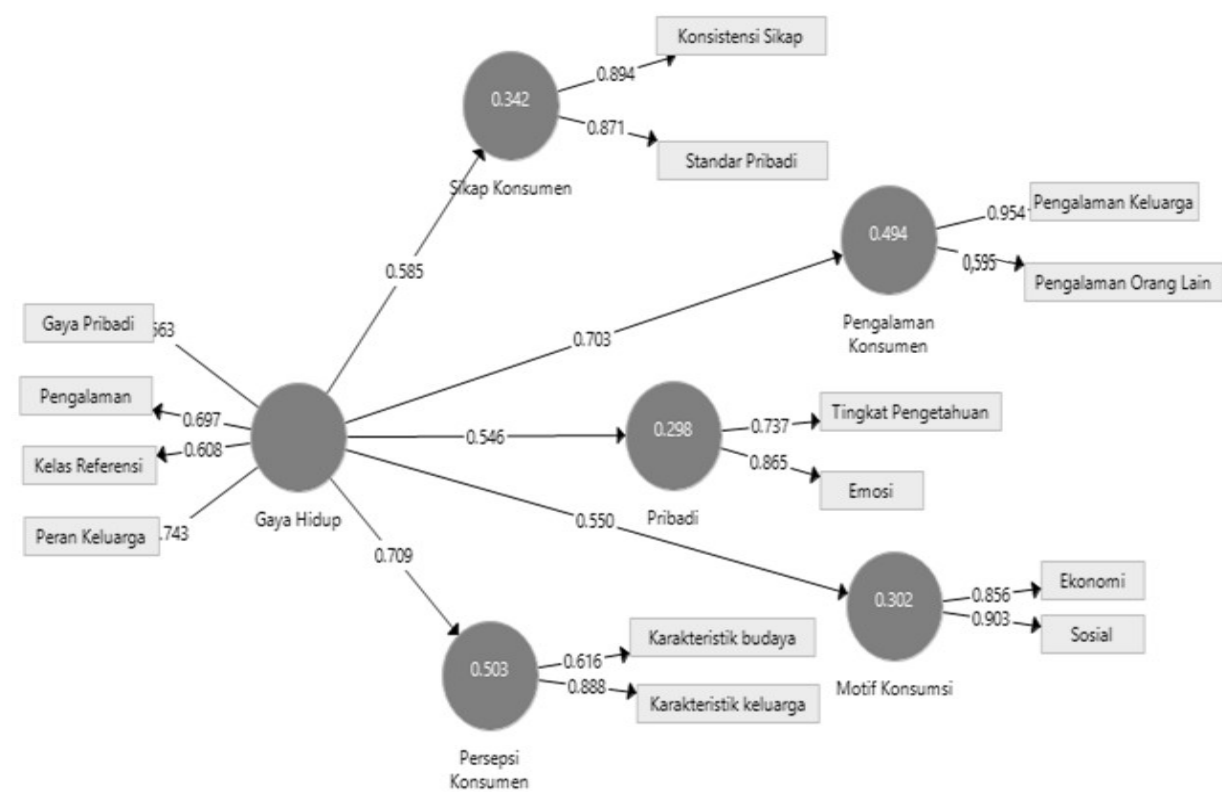

Gambar 4. Nilai factor loading variabel manifest. 
Berdasarkan gambar diatas maka variabel manifest yang dianalisis adalah faktor gaya kepribadian generasi muda, pengalaman, kelas referensi, peranan keluarga, konsistensi sikap, standar hidup, pengalaman keluarga dan pengalaman orang lain, tingkat pengetahuan, emosi, motif ekonomi, motif sosial, karakteristik budaya bangsa Indonesia dan karakteristik keluarga. Validitas dilanjutkan dengan uji konstruksi relibilitas dan validiti dengan menganalisi nilai Cronbach's Alpha, rho A, composite reliability dan nilai average variance extrated. Data secara detal dapat dilihat pada tabel berikut ini :

Tabel 3. Tabel Construct Reliability \&

\begin{tabular}{lcccc}
\multicolumn{5}{c}{ Validity } \\
\hline & $\begin{array}{c}\text { Cronbach's } \\
\text { Alpha }\end{array}$ & rho_A & $\begin{array}{c}\text { Composite } \\
\text { Reliability }\end{array}$ & $\begin{array}{c}\text { Average } \\
\text { Variance } \\
\text { Extracted } \\
\text { (AVE) }\end{array}$ \\
\hline $\begin{array}{l}\text { Gaya Hidup } \\
\text { Motif }\end{array}$ & 0,553 & 0,588 & 0,747 & 0,432 \\
$\begin{array}{l}\text { Konsumsi } \\
\begin{array}{l}\text { Pengalaman } \\
\text { Konsumen }\end{array}\end{array}$ & 0,711 & 0,731 & 0,873 & 0,774 \\
$\begin{array}{l}\text { Persepsi } \\
\text { Konsumen }\end{array}$ & 0,350 & 0,653 & 0,708 & 0,575 \\
$\begin{array}{l}\text { Pribadi } \\
\text { Sikap } \\
\text { Konsumen }\end{array}$ & 0,459 & 0,498 & 0,782 & 0,644 \\
\hline
\end{tabular}

Dengan menggunakan nilai composite reliability, dapat dinyatakan bahwa seluruh nilai variabel laten eksogen bernilai diatas 0,6 yang menunjukkan bahwa seluruh variabel eksogen dalam model sudah baik.

Uji permodelan sistem gaya hidup maka perlu dilakukan uji kesesuaian model. Uji dilakukan dengan menggunakan adjusted $R$ Square test. Berdasarkan hasil pengolaha data disebutkan bahwa nilai R2 adalah 0,707. Angka ini menunjukkan bahwa seluruh variabel laten eksogen substansial dan mampu menjelaskan variabel gaya hidup sebesar 70,7 persen.

Pengujian secara individual melalui nilai $f$ square menunjukkan bahwa seluruh variabel laten eksogen signifikan dan memiliki pengaruh kuat terhadap tatanan struktural model penelitian ini. Data rinci nilai $f$ square dapat dilihat pada tabel berikut ini :

Tabel 5. Nilai f Square.

\begin{tabular}{lccccc}
\hline & $\begin{array}{c}\text { Original } \\
\text { Sample }\end{array}$ & $\begin{array}{c}\text { Sample } \\
\text { Mean }\end{array}$ & $\begin{array}{c}\text { Standard } \\
\text { Deviation }\end{array}$ & $\begin{array}{c}\mathrm{T} \\
\text { Statistics }\end{array}$ & $\begin{array}{c}\mathrm{P} \\
\text { Values }\end{array}$ \\
\hline $\begin{array}{l}\text { Motif } \\
\text { Konsumsi } \rightarrow\end{array}$ & 0,433 & 0,475 & 0,238 & 1,822 & 0,035 \\
$\begin{array}{l}\text { Gaya Hidup } \\
\text { Pengalaman } \\
\rightarrow \text { Gaya Hidup }\end{array}$ & 0,976 & 1,117 & 0,373 & 2,615 & 0,005 \\
$\begin{array}{l}\text { Persepsi } \\
\text { Konsumen } \rightarrow \\
\text { Gaya Hidup }\end{array}$ & 1,011 & 1,119 & 0,298 & 3,395 & 0,000 \\
$\begin{array}{l}\text { Pribadi } \rightarrow \\
\text { Gaya Hidup }\end{array}$ & 0,425 & 0,467 & 0,186 & 2,285 & 0,012 \\
$\begin{array}{l}\text { Sikap } \\
\text { Konsumen } \rightarrow \\
\text { Gaya Hidup }\end{array}$ & 0,519 & 0,590 & 0,233 & 2,227 & 0,013 \\
\hline
\end{tabular}

Analisis jalur antar variabel dalam model penelitian ini dilakukan dengan path analysis. Berdasarkan hasil penelitian ditunjukkan bahwa variabel laten eksogen kepribadian $(P$ values $>0,05)$ yang tidak signifikan, sementara variabel lainnya signifikan $(P$ values $<0,05)$ dan memiliki hubungan positif. Secara detail, nilai analisis path dapat dilihat pada tabel berikut:

Tabel 6. Hasil Path Analysis.

\begin{tabular}{|c|c|c|c|c|c|}
\hline & Original & Sample & Standard & $T$ & $P$ \\
\hline & Sample & Mean & Deviation & Statistics & Values \\
\hline Motif & 0,316 & 0,315 & 0,117 & 2,706 & 0,007 \\
\hline $\begin{array}{l}\text { Konsumsi } \rightarrow \\
\text { Gaya Hidup }\end{array}$ & & & & & \\
\hline $\begin{array}{l}\text { Pengalaman } \\
\rightarrow \text { Gaya } \\
\text { Hidup }\end{array}$ & 0,474 & 0,466 & 0,098 & 4,848 & 0,000 \\
\hline $\begin{array}{l}\text { Persepsi } \\
\text { Konsumen } \\
\rightarrow \text { Gaya } \\
\text { Hidup }\end{array}$ & 0,228 & 0,230 & 0,076 & 2,986 & 0,003 \\
\hline $\begin{array}{l}\text { Pribadi } \rightarrow \\
\text { Gaya Hidup }\end{array}$ & $-0,099$ & $-0,082$ & 0,106 & 0,844 & 0,400 \\
\hline $\begin{array}{l}\text { Sikap } \\
\text { Konsumen } \\
\rightarrow \text { Gaya } \\
\text { Hidup }\end{array}$ & 0,164 & 0,160 & 0,079 & 2,079 & 0,039 \\
\hline
\end{tabular}

Analisis terhadap korelasi antara variabel laten manifes, menunjukkan nilai yang signifikan. Dan berdasarkan nilai koefisien menunjukkan nilai positif. Secara detail, data nilai outer loading dapat dilihat pada tabel berikut ini. 
Tabel 7. Hasil Outer Loadings.

\begin{tabular}{|c|c|c|c|c|c|}
\hline & $\begin{array}{l}\text { Original } \\
\text { Sample }\end{array}$ & $\begin{array}{l}\text { Sample } \\
\text { Mean }\end{array}$ & $\begin{array}{l}\text { Standard } \\
\text { Deviation }\end{array}$ & $\begin{array}{c}{ }^{\top} \\
\text { Statistics }\end{array}$ & $\begin{array}{c}\mathrm{P} \\
\text { Values }\end{array}$ \\
\hline $\begin{array}{l}\text { Motif Konsumsi } \\
\rightarrow \text { Motif } \\
\text { Ekonomi }\end{array}$ & 0,854 & 0,841 & 0,113 & 7,556 & 0,000 \\
\hline Pribadi $\rightarrow$ Emosi & 0,877 & 0,873 & 0,053 & 16,414 & 0,000 \\
\hline $\begin{array}{l}\text { Gaya Hidup } \rightarrow \\
\text { kepribadian }\end{array}$ & 0,519 & 0,517 & 0,131 & 3,951 & 0,000 \\
\hline $\begin{array}{l}\text { Persepsi } \\
\text { Konsumen } \\
\text { 世Karakteristik } \\
\text { budaya }\end{array}$ & 0,595 & 0,271 & 0,133 & 4,474 & 0,000 \\
\hline $\begin{array}{l}\text { Persepsi } \\
\text { Konsumen } \leftarrow \\
\text { Karakteristik } \\
\text { keluarga }\end{array}$ & 0,900 & 0,904 & 0,040 & 22,729 & 0,000 \\
\hline $\begin{array}{l}\text { Gaya Hidup } \rightarrow \\
\text { Kelas Referensi }\end{array}$ & 0,568 & 0,566 & 0,104 & 2,439 & 0,000 \\
\hline $\begin{array}{l}\text { Sikap } \\
\text { Konsumen } \rightarrow \\
\text { Konsistensi } \\
\text { Sikap }\end{array}$ & 0,901 & 0,904 & 0,029 & 30,831 & 0,000 \\
\hline $\begin{array}{l}\text { Gaya Hidup } \rightarrow \\
\text { Pengalaman }\end{array}$ & 0,714 & 0,714 & 0,073 & 9,747 & 0,000 \\
\hline $\begin{array}{l}\text { Pengalaman } \\
\text { Konsumen } \\
\rightarrow \text { Pengalaman } \\
\text { Keluarga }\end{array}$ & 0.960 & 0,955 & 0,025 & 38,338 & 0,000 \\
\hline $\begin{array}{l}\text { Pengalaman } \\
\text { Konsumen } \rightarrow \\
\text { Pengalaman } \\
\text { orang lain }\end{array}$ & 0,477 & 0,480 & 0,148 & 3,227 & 0,001 \\
\hline $\begin{array}{l}\text { Gaya Hidup } \rightarrow \\
\text { Peran Keluarga }\end{array}$ & 0,791 & 0,792 & 0,053 & 14,934 & 0,000 \\
\hline $\begin{array}{l}\text { Motif Konsumsi } \\
\rightarrow \text { Motif Sosial }\end{array}$ & 0,905 & 0,907 & 0,043 & 21,238 & 0,000 \\
\hline $\begin{array}{l}\text { Sikap } \\
\text { Konsumen } \rightarrow \\
\text { Standar Pribadi }\end{array}$ & 0,863 & 0,860 & 0,050 & 17,407 & 0,000 \\
\hline $\begin{array}{l}\text { Pribadi } \rightarrow \\
\text { Tingkat } \\
\text { Pengetahuan }\end{array}$ & 0,720 & 0,705 & 0,114 & 6,309 & 0,000 \\
\hline
\end{tabular}

\section{Pembahasan}

Hasil analisis terhadap analisis pola jalur, menunjukan bahwa semakin tinggi sikap konsumen yang menghargai produk dalam negeri, sebesar satu satuan maka gaya hidup cinta produk makanan dalam negeri juga akan meningkat sebesar 0,164. Penyataan ini sejalan dengan penelitian Maio et al yang menyebutkan bahwa sebagian besar penelitian perubahan sosial harus mempertimbangkan intervensi dari faktor sikap, kepercayaan dan perilaku (Maio et al., 2007b). Nilai koefisien parameter motif konsumsi menunjukkan bahwa semakin tinggi motif konsumsi sebesar satu satuan maka gaya hidup cinta produk makanan dalam negeri dengan nilai sebesar 0,316. Satu satuan makin tinggi pengalaman yang menyenangkan dari konsumsi produk makanan dalam negeri maka gaya hidup cinta produk makanan dalam negeri meningkat sebesar 0,474 satuan. Motif dan pengalaman generasi muda terhadap perubahan gaya hidup juga dianalisis oleh Iqbal, et al yang menganalisis perubahan pola anak-anak terhadap platform media virtual (Iqbal, Kankaanranta and Neittaanmäki, 2010). Persepsi konsumen mengenai nilai perjuangan atas konsumsi produk dalam negeri akan meningkatkan 0,228 satuan gaya hidup cinta produk makanan dalam negeri. Faktor persepsi dibentuk dari etnis budaya dimana perubahan perspsi konsumen yang berbasis kelompok etnis memiliki pengaruh yang signifikan terhadap perubahan pola gaya hidup (Licsandru and Cui, 2019; Bruce et al., 2019).

Hasil analisis korelasi antara variabel manifest terhadap variabel laten, menunjukkan semua variabel signifikan. Dengan nilai korelasi antara nilai 0,568 sampai dengan 0,960. Analisis ini menunjukan bahwa ternyata ada hubungan reflektif antara gaya hidup dengan kepribadian $(0,519)$, kelas referensi $(0,568)$, pengalaman konsumen $(0,714)$ dan peran keluarga $(0,791)$. Hasil ini didukung oleh penelitian Towaliu dan Tumbuan (2017) yang menyebutkan bahwa dalam keputusan pembelian konsumen di rumah makan Warung Tepi Laut Menado, dipengaruhi oleh faktor pribadi dan keluarga. Dimana dengan memberikan kenyamanan kepada konsumen, maka akan membentuk gambaran positif didalam keluarga dan tersebar diantara masing-masing anggota keluarga (Towoliu and Tumbuan, 2017; Maryani, Kristiana and Lestari, 2017). Penelitian Aresa (2012) juga menyebutkan bahwa gaya hidup generasi muda akan sangat mempengaruhi pembelian kembali produk-produk makanan dan minuman di "7 Eleven" Tebet Saharjo sehingga produsen harus memperhatikan perubahan gaya hidup konsumennya (Ashoer, Syahnur and Murdifin, 2019; Aresa, 2012). 
Sikap konsumen dalam penelitian ini sistem nilai, konsistensi sikap itu sendiri dan standar pribadi. Nilai dan standar pribadi diarahkan pada sikap patriotisme generasi muda. Nilai yang dianut bahwa dengan mengkonsumsi produk dalam negeri maka merupakan pencerminan sikap patriotisme. Apabilai nilai dan standar pribadi ini dapat ditingkatkan maka gaya hidup cinta produk dalam negeri pada generasi muda dapat konsisten. Dan ternyata dalam penelitian sikap konsumen memang mempengaruhi konsistensi sikap generasi muda untuk cinta produk dalam negeri $(0,901)$ dan standar pribadi $(0,863)$. Penelitian Harsita dan Amam (2019) mengenai sikap konsumen muda terhadap konsumsi produksi turunan singkong. Singkong bagi generasi muda dimaknakan makanan tidak spesial dan biasa. Namun berdasarkan penelitian ini, ternyata generasi muda memiliki sikap yang positif (Harsita and Amam, 2019). Penelitian Pasaribu, Rafi dan Khairawati (2017) mengenai persepsi generasi $\mathrm{Y}$ terhadap produk kerajinan tangan daerah menunjukkan bahwa generasi $\mathrm{Y}$ cenderung memiliki persepsi bahwa kerajinan tangan khas daerah adalah produk yang kurang menarik dibandingkan produk luar dan bersifat hanya sebagai pelengkap (Pasaribu, Rafi and Khairawati, 2017).

Variabel pengalaman ternyata dipengaruhi secara positif oleh faktor pengalaman keluarga $(0,960)$ dan pengalaman orang lain $(0,477)$. Manusia pada dasarnya adalah mahluk sosial. Keluarga merupakan faktor pertama yang mempengaruhi pola konsumsi. Sehingga wajar jika pengalaman keluarga dan orang lain akan membentuk pengalaman terhadap produk makanan dan minuman dalam negeri, terutama produk warteg. Penelitian Fauzie et al (2016) menyatakan bahwa pengalaman konsumen yang positif memiliki pengaruh terhadap keputusan pembelian ayam merk KFC cabang Mall Olympic Garden Malang (Fauzie, Yulianto and Sunarti, 2016).
Variabel kepribadian ternyata dipengaruhi secara positif dan erat dengan emosi generasi muda $(0,877)$ dan tingkat pengetahuan $(0,720)$. Pada dasarnya emosi akan membentuk perasaaan konsumen terhadap produk. Faktor emosi dalam penelitian ini didekati dengan perasaan senang dan bangga terhadap produk dalam negeri. Semakin tinggi pengaruh faktor emosi ini maka diharapkan memperkuat kepribadian generasi muda terhadap cinta produk dalam negeri. Penelitian mengenai perasaan konsumen terhadap keputusan pembelian air mineral Ades dilakukan oleh Lestari (2013) yang menyatakan bahwa pengetahuan, perasaan, kepercayaan dan motivasi mempengaruhi pemasaran hijau produk air dalam kemasan merek ADES. Pengetahuan konsumen mengenai konsep produk dalam negeri juga membantu generasi muda untuk membentuk kepribadiannya agar cinta produk dalam negeri.

Variabel motif dalam mengkonsumsi produk dalam negeri mempengaruhi motif ekonomi $(0,854)$ dan motif sosial $(0,905)$. Motif ekonomi dan motif sosial termasuk kedalam hal penting dalam upaya peningkatan cinta produk dalam negeri. Motif ekonomi, menjadi pembatas dalam konsumsi produk makanan dan minuman dalam negeri. Hal ini terjadi karena produk makanan dan minuman dalam negeri cenderung lebih murah dibandingkan produk luar negeri tapi dari motif sosial terkait gengsi, maka produk luar negeri akan jauh lebih bergengsi dikalangan generasi muda. Penelitian Siswadi (2014) menyebutkan bahwa persepsi mahasiswa terhadap keberadaan pedagang kaki lima disekitar kampus pada dasarnya membantu pemenuhan kebutuhan sehari-hari mahasiswa, mudah dijangkau, murah walaupun seringkali kualitas produk kurang memuaskan (Siswadi, 2014).

Variabel persepsi konsumen terhadap cinta produk dalam negeri dalam penelitian ini dipengaruhi oleh karateristik budaya 
$(0,595)$ dan Karakteristik keluarga $(0,900)$. Pada dasarnya karakteristik budaya akan bercampur dalam karakteristik keluarga. Proteksi budaya memegang perana penting dalam pembentukan persepsi generasi muda terhadap produk dalam negeri. Hal ini senada dengan penelitian Munfarida (2012) yang meyebutkan bahwa internalisasi budaya hemat akan mampu membatasi hasrat konsumeristik dikalangan generasi muda (Munfarida, 2012). Dan bila internalisasi budaya hemat ini diterapkan oleh sesama anggota keluarga, maka persepsi konsumen akan semakin baik terhadap produk dalam negeri. Penelitian Setianingsih tahun 2018, menunjukkan bahwa faktor status sosial orang tua dan gaya hidup cenderung mempengaruhi perilaku konsumtif dikalangan mahasiswa (Setianingsih, 2018).

Implikasi dari penelitian ini adalah bagi produsen warung tegal, harus mampu memberikan pengalaman yang menyenangkan bagi generasi muda serta harga jual yang kompetitif. Pengalaman yang menyenangkan yang diharapkan konsumen generasi muda adalah bahwa kebersihan makanan, tempat dan alat makan, serta kenyamanan dan menu yang segar dan sehat. Hal ini menjadi penting karena variabel pengalaman memiliki nilai koefisien regresi $(0,474)$ yang paling besar terhadap gaya hidup cinta produk makanan dan minuman dalam negeri dengan tetap menjaga harga jual yang kompetitif dengan produk makanan dari luar negeri karena variabel motif ekonomi terkait harga jual warteg yang terjangkau oleh generasi muda. Perlu dipahami bahwa generasi muda saat ini cenderung mencoba semua produk, memilih produk berdasarkan kemauan dan identitas individu mereka sendiri, memiliki kemampuan menciptakan trend, dan kemudian mereka dapat mempengaruhi konsumsi rekan-rekannya (Moreno et al., 2017).

\section{SIMPULAN}

Gaya hidup cinta produk dalam negeri, pada dasarnya dapat didekati melalui motif konsumsi, pengalaman atas produk baik berupa pengalaman diri sendiri, keluarga maupun orang lain dalam kelompok. Faktor lainnya adalah peningkatan persepsi konsumen mengenai nilai cinta bangsa dan negara yang berbentuk tindakan konsumsi produk dalam negeri. Dan diharapkan dengan peningkatan persepsi akan membentuk sikap cinta produk makanan dalam negeri dikalangan generasi muda Indonesia. Tim peneliti mengucapkan terima kasih kepada IBI Kosgoro 1957 yang telah mendanai dan memfasilitasi penelitian ini.

\section{REFERENSI}

Ahmed, H. O. et al. (2018) 'The life styles causing overweight or obesity: Based on 5 years of experience in two centers in Sulaimani Governorate, Kurdistan Region/Iraq', International Journal of Surgery Open. Elsevier Ltd, 11, pp. 2229. doi: 10.1016/j.ijso.2018.04.002.

Ahuvia, A., Carroll, B. and Yang, Y. (2016) 'Consumer Culture Theory And Lifestyle Segmentation', Innovative Marketing, 2(4), pp. 33-43. doi: 10.4324/9781315675015.

Andayani, S. W. (2015) 'Faktor-Faktor Yang Mempengaruhi Minat Konsumen Dalam Mengkonsumsi Makanan Tradisional Daerah Tegal Di Warung Tegal (Warteg) Balek Maning Yogyakarta', Jurnal Akademik Universitas Sarjanawiyata Tamansiswa (UST) Yogyakarta, September, pp. 6571.

Andriyanty, R. and Wahab, D. (2019) 'Preferensi Konsumen Generasi Z Terhadap Konsumsi Produk Dalam Negeri', Ethos, 7(2), pp. 280-296.

Aresa, D. (2012) Pengaruh Gaya Hidup Terhadap Repurchase Intention (Studi Pada Pengunjung 7 Eleven Tebet 
Saharjo), Skripsi Pada UI, Depok.

Asayesh, M. H. and Hamid, B. (2011)

'Examination of personal values system and its changes among young people', Procedia - Social and Behavioral Sciences, 30, pp. 1390-1394. doi: 10.1016/j.sbspro.2011.10.270.

Ashoer, M., Syahnur, H. and Murdifin, I. (2019) 'Bagaimana Gaya Hidup mempengaruhi Keputusan Pembelian Tiket Online?', Jurnal Ilmiah Manajemen Dan Bisnis, 20(1), pp. 5265. doi: 10.30596/jimb.v20i1.2493.

Boeree, C. G. et al. (2006) 'Alfred Adler [ 1870 - 1937 ]', in Personality Theories, pp. 1-14.

Bruce, H. L. et al. (2019) 'Resource integration, value creation and value destruction in collective consumption contexts', Journal of Business Research. Elsevier, 103(May), pp. 173185. doi: 10.1016/j.jbusres.2019.05.007.

Budac, C. and Baltador, L. A. (2014) 'Brand Communication Challenges in Getting Young Customer Engagement', Procedia Economics and Finance. Elsevier B.V., 16(May), pp. 521-525. doi: 10.1016/s2212-5671(14)00833-8.

Dascălu, D. I. (2014) 'Individualism and mass communication in the context of globalization', Procedia - Social and Behavioral Sciences, 163, pp. 1-6. doi: 10.1016/j.sbspro.2014.12.278.

Eren, S. S., Eroğlu, F. and Hacioglu, G. (2012) 'Compulsive Buying Tendencies through Materialistic and Hedonic Values among College Students in Turkey', Procedia - Social and Behavioral Sciences, 58, pp. 13701377. doi: 10.1016/j.sbspro.2012.09.1121.

Fauzie, D., Yulianto, E. and Sunarti (2016) 'Pengaruh Faktor Psikologis Konsumen Terhadap Keputusan Pembelian ( Survei Pada Konsumen KFC Cabang Mall Olympic Garden Malang )', Jurnal
Administrasi Bisnis, 40(1), pp. 1-7.

Hamzah, S. R. et al. (2014) 'The Influence of Religiosity, Parental and Peer Attachment on Hedonistic Behavior among Malaysian Youth', Procedia Social and Behavioral Sciences. Elsevier B.V., 122, pp. 393-397. doi: 10.1016/j.sbspro.2014.01.1360.

Harsita, P. A. and Amam (2019) 'Analisis Sikap Konsumen Terhadap Produk Olahan Singkong', Agrisocionomics, 3(1), pp. 19-27.

Iqbal, A., Kankaanranta, M. and Neittaanmäki, P. (2010) 'Experiences and motivations of the young for participation in virtual worlds', Procedia - Social and Behavioral Sciences. Elsevier Ltd, 2(2), pp. 31903197.

doi:

10.1016/j.sbspro.2010.03.488.

Jasimah bt. Wan Mohamed Radz, C. W., Murad, M. H. S. A. and Osman, B. (2005) 'Food Intake In Malaysian Culture And Society: Focus On The Younger Generation', Science and Technology Studies, 29(5), pp. 1-11.

Jensen, M. (2007) ' Defining lifestyle ', Environmental Sciences, 4(2), pp. 6373. doi: $10.1080 / 15693430701472747$.

Joshi, A. B. (2012) 'New Generation Youth Lifestyle and Food Consumption Pattern', SSRN Electronic Journal, (October 2012). doi: $10.2139 /$ ssrn. 2157400 .

Karoui, S. and Khemakhem, R. (2019) 'Consumer ethnocentrism in developing countries', European Research on Management and Business Economics. AEDEM, 25(2), pp. 63-71. doi: 10.1016/j.iedeen.2019.04.002.

Licsandru, T. C. and Cui, C. C. (2019) 'Ethnic marketing to the global millennial consumers: Challenges and opportunities', Journal of Business Research. Elsevier, 103(February), pp. 261-274. doi: 10.1016/j.jbusres.2019.01.052. 


\section{Jurnal Ilmiah Manajemen dan Bisnis}

Maio, G. R. et al. (2007a) 'Social Psychological Factors in Lifestyle Change and Their Relevance to Policy', Social Issues and Policy Review, 1(1), pp. 99-137. doi: 10.1111/j.17512409.2007.00005.x.

Maio, G. R. et al. (2007b) 'Social Psychological Factors in Lifestyle Change and Their Relevance to Policy', Social Issues and Policy Review, 1(1), pp. 99-137. doi: 10.1111/j.17512409.2007.00005.x.

Maryani, H., Kristiana, L. and Lestari, W. (2017) 'Faktor Dalam Pengambilan Keputusan Pembelian Jamu Saintifik', Buletin Penelitian Sistem Kesehatan, 19(3).

doi:

10.22435/hsr.v19i3.6327.200-210.

Moreno, F. M. et al. (2017) 'The Characterization of the Millennials and Their Buying Behavior', International Journal of Marketing Studies, 9(5), p. 135. doi: 10.5539/ijms.v9n5p135.

Munfarida, E. (2012) 'Peran Keluarga Di Era Budaya Konsumen', KOMUNIKA: Jurnal Dakwah dan Komunikasi, 6(1), pp. 1-19. doi: 10.24090/komunika.v6i1.333.

Novianti, M. D. et al. (2018) 'Kajian Identifikasi Faktor Untuk Pengembangan Usaha Warung Tegal ( Warteg ) Masuk Mall ( Studi Kasus Di Jabodetabek )', 1(September), pp. 143150.

Özdemir, B. and Kongresi, Z. K. (2019) 'Hedonism and Food Attributes As Predictors of Street Foods Consumption2',

Izmirgastrotourismcongress.Com, (January). Available at: http://www.izmirgastrotourismcongress. com/dosya/74/bildirikitabi_74_4833535.pdf\#page $=29$.

Pasaribu, H., Rafi, C. and Khairawati (2017) 'Persepsi Generasi Y Terhadap Kerajinan Tangan Daerah', Jurnal Ilmiah Manajemen \& Bisnis, 18(2), pp.
212-219.

Ramadania, Gunawan, S. and Rustam, M. (2015) 'Cultural Similarity, Consumer Ethnocentrism and Product Necessity in Evaluation of Malaysian Products: Indonesian Consumer Perspective', Procedia - Social and Behavioral Sciences, 211, pp. 533-540. doi: 10.1016/j.sbspro.2015.11.071.

Ramadhan, A. F. and Simanjuntak, M. (2018) 'Perilaku Pembelian Hedonis Generasi Z: Promosi Pemasaran, Kelompok Acuan dan Konsep Diri', Jurnal Ilmu Keluarga Dan Konsumen, 11(3), pp. 243-254. doi: http://dx.doi.org/10.24156/jikk.2018.11. 3.243 .

Ramdhon, A. (2018) 'WARUNG TEGAL: RELASI KAMPUNG MENYANGGA KOTA JAKARTA ( Studi Kasus Pada Warung Tegal di Jakarta Timur ) Program Studi Sosiologi Fakultas Ilmu Sosial dan Politik Universitas Sebelas Maret Surakarta Indonesia, 1(2), pp. 159-166.

Rizi, G. S. and Sabeghi, M. (2015) 'Study of the Role of Identity in Lifestyle and Consumption', 5, pp. 14-21.

Sathish, S. and Rajamohan, a (2012) 'Consumer behaviour and lifestyle marketing', International Journal of Marketing, Financial Services \& Management Research, 1(10), pp. 152166.

Setianingsih, S. A. (2018) Pengaruh Status Sosial Ekonomi Orang Tua dan Gaya Hidup Terhadap Perilaku Konsumtif Mahasiswa, IAIN Purwokerto. doi: 10.1051/matecconf/201712107005.

Sharif, M. S. M. et al. (2013) 'Factors that Restrict Young Generation to Practice Malay Traditional Festive Foods', Procedia - Social and Behavioral Sciences. Elsevier B.V., 101, pp. 239247. doi: 10.1016/j.sbspro.2013.07.197. Siswadi, Y. (2014) 'Persepsi Mahasiswa Tentang Keberadaan Pedagang Kaki 


\section{Jurnal Ilmiah Manajemen dan Bisnis}

Lima Di Sekitar Kampus', Jurnal Manajemen \& Bisnis, 14(02), pp. 166175.

Ting, H. et al. (2018) 'Are we Baby Boomers, Gen $\mathrm{X}$ and Gen Y? A qualitative inquiry into generation cohorts in Malaysia', Kasetsart Journal of Social Sciences. Elsevier Ltd, 39(1), pp. 109115. doi: 10.1016/j.kjss.2017.06.004.

Tittenbrun, J. (2017) 'Weberian Controversiers', (November).

Towoliu, J. E. and Tumbuan, W. J. F. . (2017) 'Pengaruh Faktor Pribadi Dan Faktor Keluarga Terhadap Keputusan
Pembelian Di Rumah Makan Waroeng Tepi Laut, Menado', EMBA, 5(2), pp. 308-322.

Uth, T. C., Lahrmann, H. and Pedersen, L. H. (1996) 'Definitions of life style and its application to travel behavior', Trafikdage på Aalborg Universitet Denmark, pp. 531-544.

Veal, A. J. (1993) 'The concept of lifestyle: A review', Leisure Studies, 12(4), pp. 233-252. doi: 